\title{
KIT NM_000222.2:C.1669T>A
}

National Cancer Institute

\section{Source}

National Cancer Institute. KIT NM 000222.2:C.1669T>A. NCI Thesaurus. Code C158897.

A nucleotide substitution at position 1669 of the coding sequence of the KIT gene where thymine has been mutated to adenine. 